\title{
PERBANDINGAN HASIL EKSPERIMEN DAN MODIFIKASI ALAT PENGUJIAN SEISMIK DENGAN HASIL KORELASI DATA N-SPT DAN CPT
}

\author{
Gebby Pandu ${ }^{1}$, Ali Iskandar ${ }^{2}$ dan Sunarjo Leman ${ }^{3}$ \\ ${ }^{1}$ Program Studi Sarjana Teknik Sipil, Universitas Tarumanagara, Jl. Letjen S. Parman No.1 Jakarta \\ Email: gebbii.winata@gmail.com \\ ${ }^{2}$ Program Studi Sarjana Teknik Sipil, Universitas Tarumanagara, Jl. Letjen S. Parman No.1 Jakarta \\ Email: ali.iskandar1999@gmail.com \\ ${ }^{3}$ Program Studi Sarjana Teknik Sipil, Universitas Tarumanagara, Jl. Letjen S. Parman No.1 Jakarta \\ Email: sunarjo@ft.untar.ac.id
}

\begin{abstract}
ABSTRAK
Dengan letak Indonesia yang strategis secara geografis dan geologis, tanah di Indonesia memiliki potensi gempa yang berbeda-beda di setiap wilayahnya. Keadaan tersebut perlu diantisipasi agar dapat mencegah kerusakan fatal ataupun hal-hal yang tidak diinginkan akibat gempa bumi, sehingga perlu diketahui karakteristik tiap lapisan tanah di masing-masing titik pada lokasi tersebut. Salah satunya adalah dengan mengetahui cepat rambat gelombang geser yang didapatkan dari pengujian seismik. Pengujian seismik yang dilakukan pada penelitian ini ada Downhole Seismic, Crosshole Seismic, dan juga modifikasi alat $P$-S Suspension dengan kedalaman borehole 30 meter dan interval pengujian 1 meter. Demi kelancaran penelitian ini, ketiga pengujian tersebut dibantu dengan alat-alat pengujian dari Olson Instruments dan juga software Wingeo dan Microsoft Excel. Adapun lokasi pengujian yang bertempatkan di Kantor PT. Tarumanegara Bumiyasa. Setelah dilakukan pengolahan data, analisis, dan perbandingan hasil dari ketiga pengujian terhadap hasil berdasarkan data N-SPT dan Sondir dari rumus empiris, didapatkan bahwa pengujian Crosshole Seismic yang paling sesuai dan akurat untuk menentukan hasil cepat rambat gelombang geser. Sedangkan, modifikasi alat $P$-S Suspension belum dapat digunakan untuk pengujian ini berdasarkan hasil yang ditunjukkan melenceng jauh, khususnya pada kedalaman yang mendekati permukaan. Namun dapat dikembangkan lagi untuk penelitian selanjutnya dengan rancangan yang lebih baik, penambahan uji dengan arah piston yang mengarah ke geofon, dan juga lokasi yang lebih sunyi untuk mengetahui lebih maksimal apakah modifikasi alat $P-S$ Suspension layak untuk digunakan atau tidak.
\end{abstract}

Kata kunci: Downhole Seismic, Crosshole Seismic, P-S Suspension, cepat rambat gelombang geser, pengujian seismik

\section{PENDAHULUAN}

\section{Latar Belakang}

Negara Indonesia sendiri merupakan negara yang kaya akan alamnya dan juga letaknya yang strategis secara geografis dan geologis. Tidak hanya itu, Indonesia juga berada dalam ring of fire yang membuat Indonesia tidak lepas dari berbagai bencana alam, seperti gunung meletus, tsunami, gempa bumi, dan lain sebagainya. Sebagai contohnya, pada bulan Januari - Februari 2018, tercatat adanya 434 gempa bumi di Indonesia dengan kekuatan $4-7$ Skala Richter berdasarkan Badan Geologi Kementerian Energi dan Sumber Daya Mineral (ESDM). Untuk lebih tepatnya, 381 gempa bumi dengan kekuatan 4 - 4.9 Skala Richter dengan 105 di wilayah barat dan 276 kali di wilayah timur. Kemudian, 48 gempa bumi dengan kekuatan 5 - 5.9 Skala Richter dengan 11 kali di wilayah barat dan 37 kali di wilayah timur. Lalu, ada 4 gempa bumi dengan kekuatan 6 - 6.9 Skala Richter dengan 1 kali di wilayah barat dan 3 kali di wilayah timur.

Dengan demikian, tanah di Indonesia dengan potensi gempa berbeda-beda di setiap wilayah tercatat pada SNI 1726:2012. Namun, diperlukan uji seismik pada lokasi-lokasi tertentu untuk mengetahui kondisi dan sifat tanah suatu wilayah lebih detail mengenai bagaimana tanahnya akan bereaksi jika adanya gempa, lebih tepatnya untuk mengukur cepat rambat gelombang pada tanah setempat, sehingga akan lebih akurat akan penanganan terhadap antisipasi terjadinya gempa ataupun mencegah kerusakan yang dapat diakibatkan oleh gelombang seismik saat terjadinya gempa.

Besar harapan agar penelitian dengan pengujian ini dapat berdampak positif untuk kedepannya dan membantu dalam pembangunan untuk mencegah kerusakan fatal ataupun hal-hal yang tidak diinginkan saat terjadinya gempa. 


\section{Batasan Masalah}

Dengan penelitian ini, maka diadakan batasan masalah sebagai berikut.

1. Penulisan skripsi ini dibatasi pada tiga pengujian dengan metode seismik untuk menentukan cepat rambat gelombang geser, yaitu Downhole Seismic dan Crosshole Seismic, serta modifikasi alat P-S Suspension.

2. Penulisan skripsi ini dibatasi pada satu titik lokasi pengujian tanah saja sampai kedalaman 30 meter.

3. Penulisan skripsi ini dibatasi pada pengujian yang hanya menggunakan alat-alat dari Olson Instruments.

\section{Rumusan Masalah}

Dengan penjabaran dan penjelasan di atas, dapat diambil rumusan masalah seperti di bawah ini.

1. Bagaimana hasil yang didapat setelah melakukan masing-masing pengujian yang telah dipaparkan di atas?

2. Bagaimana hasil dari modifikasi alat seperti yang telah disebutkan di atas?

3. Membandingkan hasil pengujian antara ketiga metode seismik pada setiap kedalaman pada tanah yang diuji terhadap data berdasarkan N-SPT dan Sondir.

4. Bagaimana kelebihan dan kekurangan masing-masing pengujian?

\section{Tujuan Penelitian}

Adapun maksud dan tujuan dari penelitian ini adalah untuk mempelajari hasil ketiga pengujian metode seismik untuk menentukan manakah yang paling sesuai untuk pengujian cepat rambat gelombang geser dengan membandingkan hasil terhadap korelasi data N-SPT dan CPT, beserta dengan kelebihan, dan kekurangan ketiganya. Ada pula maksud dan tujuan dari penelitian ini untuk mengetahui apakah modifikasi alat P-S Suspension dapat digunakan untuk pengujian atau tidak.

\section{DASAR TEORI}

\section{Klasifikasi Gelombang Seismik}

Suatu sumber energi dapat menimbulkan bermacam-macam gelombang, masing-masing merambat dengan cara yang berbeda. Ibrahim dan Subardjo (2005) beranggapan bahwa gelombang seismik berdasarkan tempat penjalarannya terdapat dua tipe, yaitu gelombang badan (body wave) dan gelombang permukaan (surface wave). Gelombang badan (body wave) merupakan gelombang yang menjalar melalui bagian dalam bumi (interior bumi) dan biasa disebut free wave karena dapat menjalar ke segala arah dan seluruh lapisan di dalam bumi. Sedangkan, gelombang permukaan (surface wave) merupakan gelombang elastik yang menjalar sepanjang permukaan. Gelombang ini terikat sehingga harus menjalar melalui suatu lapisan atau permukaan. Dan karena gelombang ini hanya dapat menjalar pada beberapa lapisan bumi, maka pada survei seismik refkeksi tidak digunakan gelombang ini.

Adapun gelombang permukaan (body wave) terdiri dari gelombang Longitudinal dan gelombang Transversal, sedangkan gelombang permukaan terdiri dari gelombang Rayleigh dan gelombang Love.

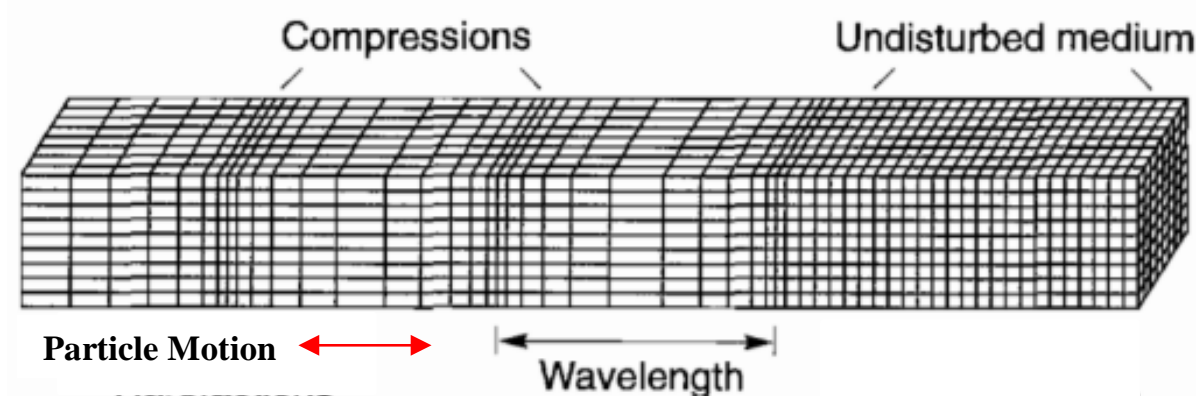

Gambar 1. Arah Gerak Partikel dan Penjalaran Gelombang Longitudinal (V $\mathrm{V}_{\mathrm{p}}$ (Bolt, 1993) 


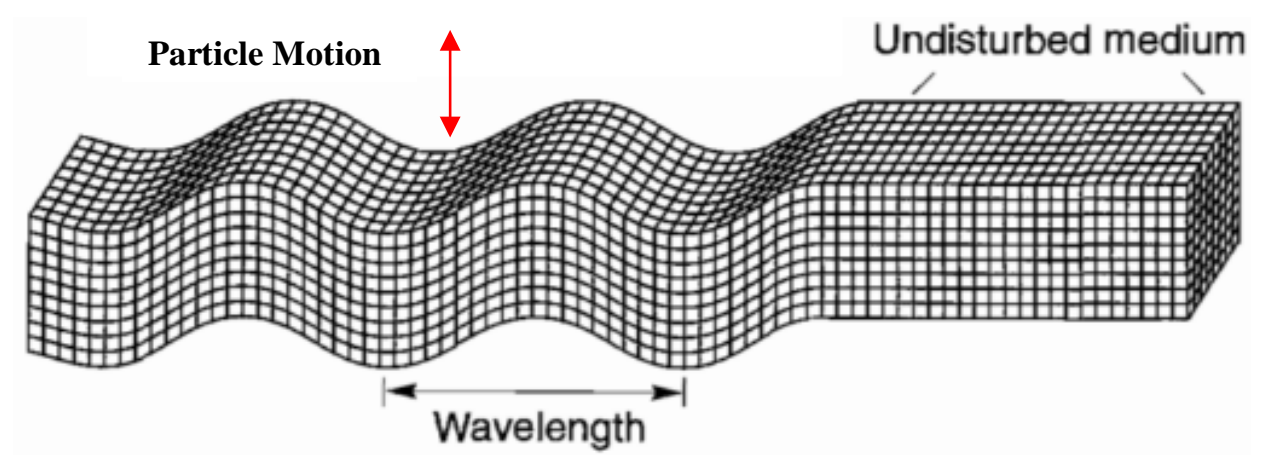

Gambar 2. Arah Gerak Partikel dan Penjalaran Gelombang Transversal (V $\mathrm{V}_{\mathrm{s}}$ ) (Bolt, 1993)

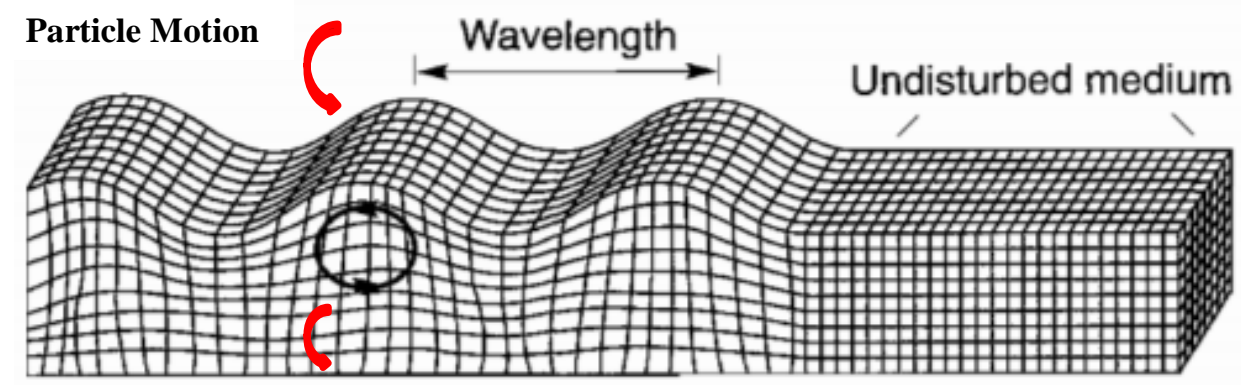

Gambar 3. Arah Gerak Partikel dan Penjalaran Gelombang Rayleigh ( $\mathrm{V}_{\mathrm{r}}$ ) (Bolt, 1993)

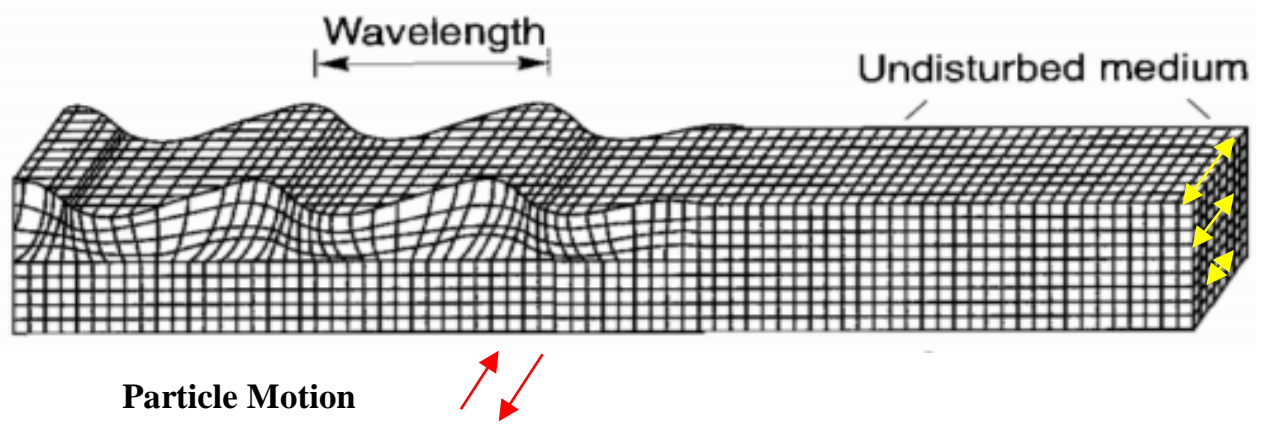

Gambar 4. Arah Gerak Partikel dan Penjalaran Gelombang Love (V $\mathrm{V}_{\mathrm{l}}$ (Bolt, 1993)

\section{Noise}

Trace yang terekam dalam pita magnetik banyak mengandung beberapa tipe gelombang termasuk noise. Noise diklasifikasikan menjadi dua sebagai berikut. (Yilmaz, 2001)

1. Noise Koheren : Noise koheren dapat terjadi berulang, berjalan secara horizontal, dan akan melemah pada arah vertikal. Namun, noise ini dapat diredam dengan beberapa cara dalam proses pengolahan. Noise koheren seperti gelombang permukaan dan refraksi.

2. Noise Tidak Koheren (Random Noise) : Noise tidak koheren ini memiliki amplitudo yang sangat tinggi dan sulit untuk diredam, kecuali dimatikan seluruhnya atau sebagian saja. Noise ini dikatakan random noise karena tidak dapat diprediksi kapan munculnya gangguan ini, sehingga noise semacam ini dapat muncul pada sembarang trace dan sembarang waktu. Hal ini dikarenakan sumber dari noise ini bukan dari gelombang yang berasal dari sumber seismik (source), tetapi dapat bersumber dari cuaca, aktifitas manusia, dan lain sebagainya.

\section{Uji Downhole Seismic}

Downhole seismic adalah salah satu metode yang digunakan untuk mengetahui sifat dan kualitas lapisan tanah berdasarkan perambatan gelombang seismik. Pada umumnya, metode ini dilakukan untuk mengetahui secara jelas sifat tanah pada lokasi-lokasi yang akan didirikan struktur atau bangunan yang memerlukan daya dukung dan 
getaran yang tinggi seperti tunnel, power house, dan lain sebagainya. Adapun ilustrasi Downhole Seismic Test seperti gambar di bawah dan acuan yang digunakan untuk melakukan pengujian, yaitu ASTM D 7400 - 08 .

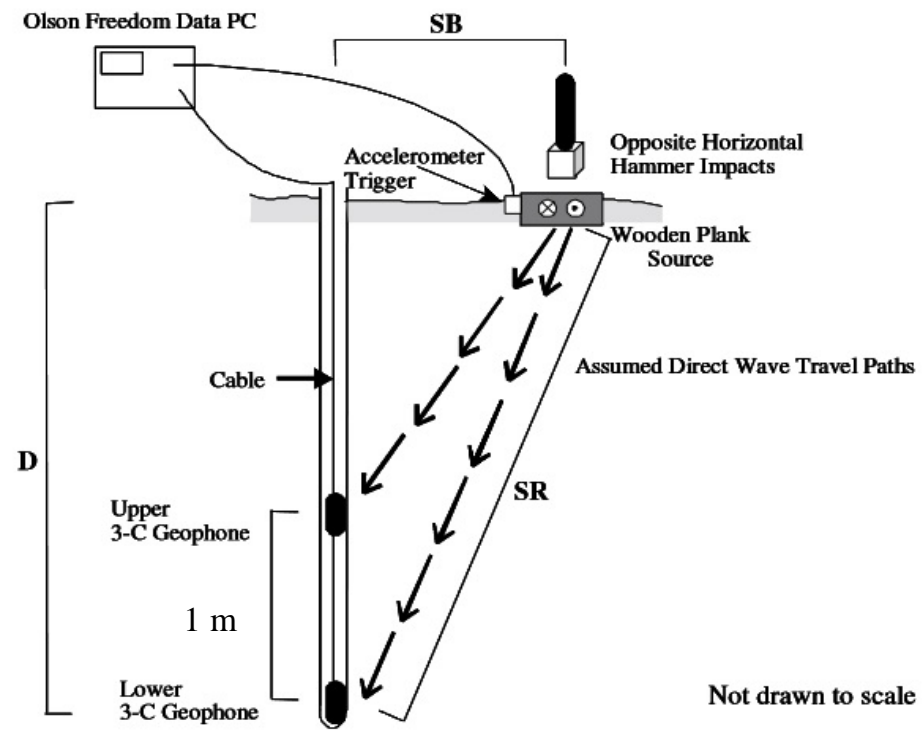

Gambar 5. Ilustrasi Uji Downhole Seismic

\section{Uji Crosshole Seismic}

Crosshole seismic adalah salah satu metode yang digunakan untuk mengukur cepat rambat gelombang seismik di antara boreholes. Pada umumnya, metode ini digunakan untuk menganalisis fondasi jembatan atau bendungan dan juga tanah likuifaksi, adapun untuk menguji material setempat, serta untuk keperluan di bidang gempa.

Kesalahan yang paling sering terjadi pada percobaan ini oleh praktisi yang kurang berpengalaman adalah mengambil energi yang terbiaskan sebagai energi yang langsung dipancarkan. Energi yang pertama kali ditangkap dapat dipengaruhi ketebalan lapisan, jarak antar lubang, dan keselarasan cepat rambat yang akhirnya menghasilkan energi pembiasan daripada energi langsung. Waktu yang terpakai oleh energi pembiasan perlu diperbaiki terlebih dahulu sebelum meng-input data tersebut ke dalam komputasi. Adapun ilustrasi Downhole Seismic Test seperti gambar di bawah dan acuan yang digunakan untuk melakukan pengujian, yaitu ASTM D 4428/D 4428M - 07.

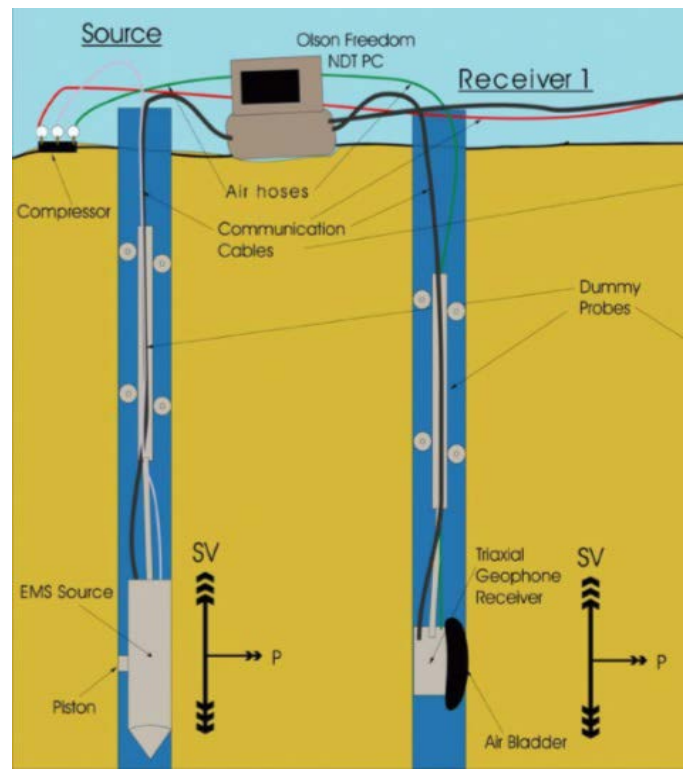

Not Drawn to Scale

Gambar 6. Ilustrasi Uji Crosshole Seismic 


\section{Uji Modifikasi Alat P-S Suspension}

P-S suspension adalah metode yang tergolong masih baru, guna untuk mengukur cepat rambat gelombang seismik. Alat ini dikembangkan pada pertengahan 1970 yang merupakan teknik yang dapat mengukur cepat rambat gelombang geser seismik dalam borehole yang dalam. Metode ini disetujui oleh Jepang pada pertengahan 1980 dan digunakan untuk mengukur komponen kecepatan lainnya dengan tujuan mengetahui respon lokasi terhadap gempa. P-S suspension kini diakui oleh Amerika, khususnya bagi peneliti dalam bidang gempa. Berikut adalah ilustrasi mengenai metode ini. Namun, alat akan dimodifikasi dengan menggunakan alat dari Olson Instruments dengan source dari uji Crosshole Seismic.

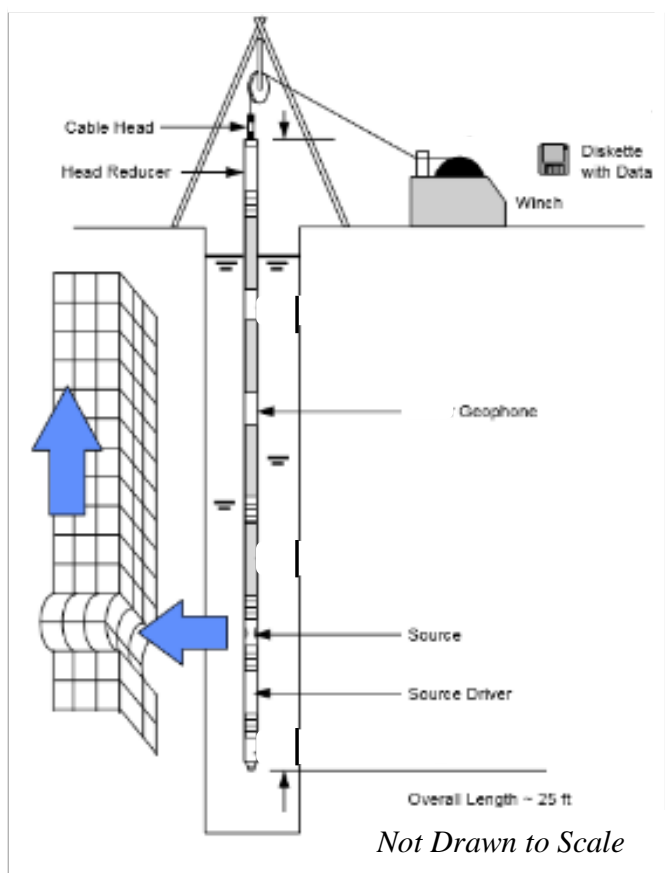

Gambar 7. Ilustrasi Uji Modifikasi Alat P-S Suspension

\section{METODOLOGI PENELITIAN}

\section{Metode Pengumpulan Data}

Data yang diperoleh dari penelitian ini berupa data primer, yaitu data yang didapatkan berdasarkan hasil pengamatan di lapangan langsung dimana percobaan metode-metode seismik ini dilaksanakan dan terekam di aplikasi WinGeo. Adapun pengumpulan data dilakukan dengan mengambil hasil uji yang dilakukan oleh salah satu perusahaan yang bergerak di bidang penyelidikan tanah sebagai bahan acuan pengujian, yaitu data hasil tes CPT (Cone Penetration Test) dan data hasil tes SPT (Standard Penetration Test).

\section{Metode Analisis Data}

Pertama-tama, dilakukan studi literatur terlebih dahulu untuk memahami pengujian yang akan dilakukan. Studi literatur dilakukan melalui buku, jurnal, dan tutorial. Hasil studi literatur digunakan sebagai landasan teori untuk melakukan pengujian dan penelitian ini. Hasil pengujian kemudian diolah pada software Wingeo dan Microsoft Excel sehingga didapatkan cepat rambat gelombang geser yang kemudian dapat dibandingkan terhadap hasil korelasi dari data CPT dan SPT.

\section{HASIL DAN PEMBAHASAN}

\section{Perbandingan Ketiga HasilPengujian Seismik}

Hasil yang didapatkan dari masing-masing pengujian seismik kemudian dibandingkan dalam bentuk grafik seperti pada gambar 8 . 


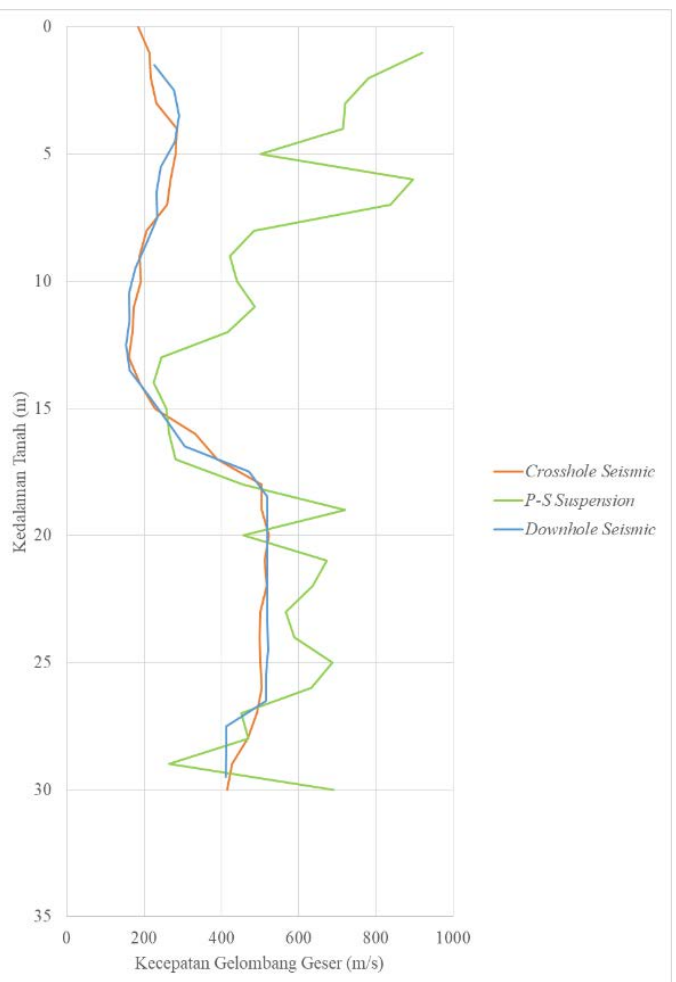

Gambar 8. Grafik Perbandingan Ketiga Hasil Pengujian

\section{Perbandingan Kedalaman Tanah dan N-SPT vs. Kecepatan Gelombang Geser Tiap Pengujian dan Hasil Korelasi Berdasarkan Data N-SPT}

Data N-SPT yang didapatkan dikorelasikan ke kecepatan gelombang geser menggunakan rumus empiris yang sudah diteliti oleh para ahli dan kemudian diambil tiga hasil yang paling mendekati hasil ketiga pengujian. Hasil ini kemudian dibuat ke dalam bentuk grafik seperti di bawah ini yang kemudian dapat menunjukkan pengujian manakah yang paling sesuai dan akurat untuk digunakan berdasarkan korelasi dari data N-SPT. Adapun grafik yang dibuat berdasarkan kedalaman tanah dan ada juga yang dibuat berdasarkan data N-SPT. Hasil yang didapatkan pun jelas terlihat bahwa pengujian $P$-S Suspension paling melenceng, sedangkan pengujian Crosshole Seismic paling akurat.

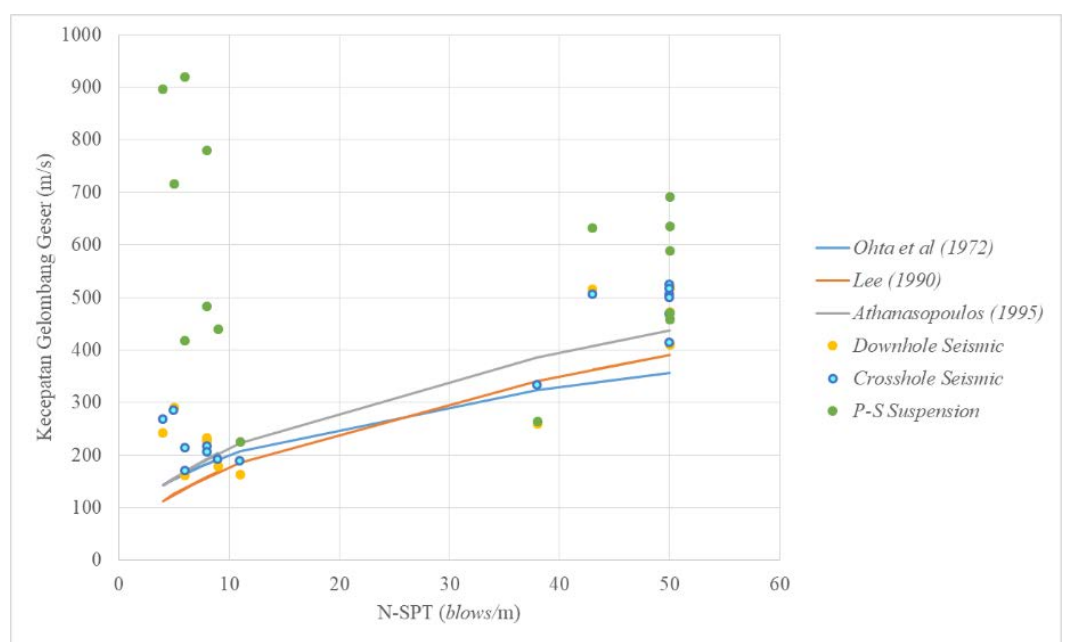

Gambar 9. Grafik Perbandingan Kecepatan Gelombang Geser vs. N-SPT Tiap Pengujian dan Hasil Korelasi Berdasarkan Data N-SPT 


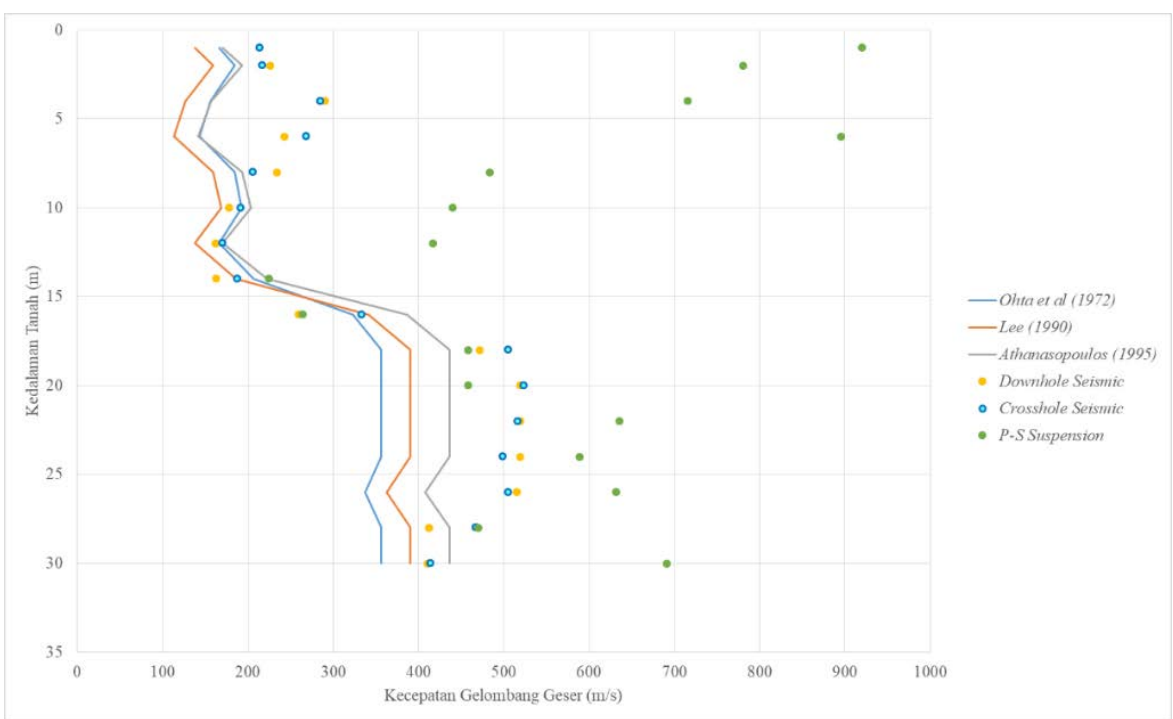

Gambar 10. Grafik Perbandingan Kedalaman Tanah vs. Kecepatan Gelombang Geser Tiap Pengujian dan Hasil Korelasi Berdasarkan Data N-SPT

\section{Perbandingan Kedalaman Tanah dan $\mathbf{q}_{c}$ vs. Kecepatan Gelombang Geser Tiap Pengujian dan Hasil Korelasi Berdasarkan Data Sondir}

Data Sondir yang didapatkan dikorelasikan ke kecepatan gelombang geser menggunakan rumus empiris yang sudah diteliti oleh para ahli dan kemudian diambil tiga hasil yang paling mendekati hasil ketiga pengujian. Hasil ini kemudian dibuat ke dalam bentuk grafik seperti di bawah ini yang kemudian dapat menunjukkan pengujian manakah yang paling sesuai dan akurat untuk digunakan berdasarkan korelasi dari data Sondir. Adapun grafik yang dibuat berdasarkan kedalaman tanah dan ada juga yang dibuat berdasarkan data Sondir. Hasil yang didapatkan pun sama seperti yang didapat berdasarkan data N-SPT, yaitu jelas terlihat bahwa pengujian P-S Suspension paling melenceng, sedangkan pengujian Crosshole Seismic lah yang paling akurat.

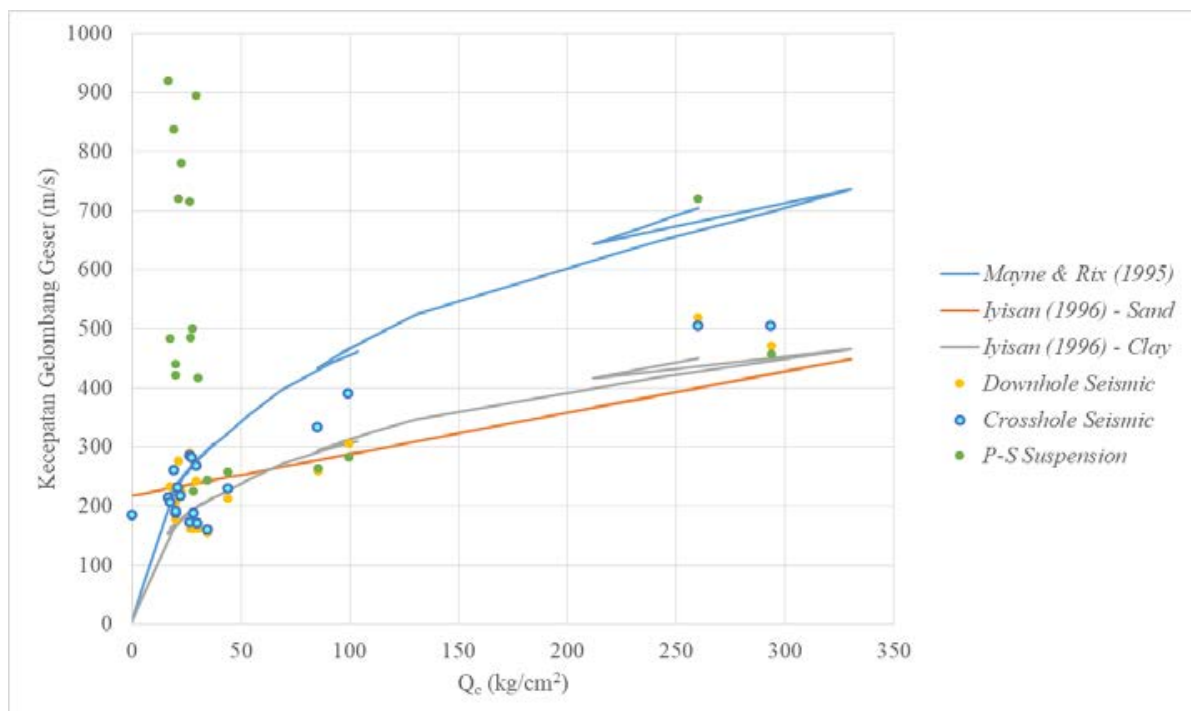

Gambar 11. Grafik Perbandingan Kecepatan Gelombang Geser vs. q Tiap Pengujian dan Hasil Korelasi Berdasarkan Data Sondir 


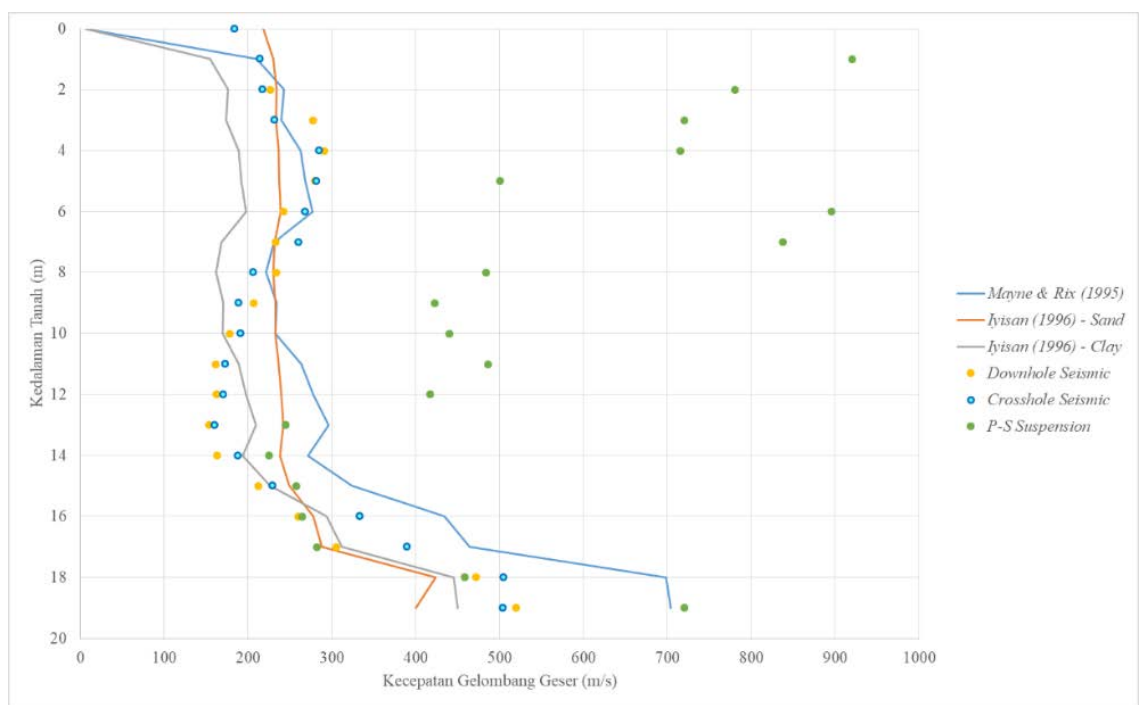

Gambar 12. Grafik Perbandingan Kedalaman Tanah vs. Kecepatan Gelombang Geser Tiap Pengujian dan Hasil Korelasi Berdasarkan Data Sondir

\section{KESIMPULAN}

Berdasarkan analisis yang telah dibahas di atas, maka dapat disimpulkan bahwa:

1. Ketiga pengujian berhasil dilakukan dengan kendala lokasi pengujian yang ramai dilewati oleh kendaraan saat pengujian, sehingga hasil yang tertangkap memiliki banyak noise dan menyulitkan penulis untuk menganalisis.

2. Hasil modifikasi alat dari pengujian P-S Suspension belum dapat digunakan untuk pengujian tanah ini, khususnya pada kedalaman yang mendekati permukaan.

3. Hasil pengujian Crosshole Seismic lah yang paling sesuai dan akurat untuk pengujian ini karena hasilnya yang paling mendekati ke hasil korelasi dari rumus empiris berdasarkan data N-SPT dan Sondir.

4. Adanya perbandingan kelebihan dan kekurangan antara masing-masing pengujian sebagai berikut.

Tabel 1. Perbandingan Kelebihan dan Kekurangan Ketiga Pengujian

\begin{tabular}{|c|c|c|c|}
\hline No. & Nama Pengujian & Kelebihan & Kekurangan \\
\hline 1. & & $\begin{array}{c}\text { Biaya yang lebih murah karena } \\
\text { penggunaan lubang bor yang hanya } \\
\text { satu dan source yang hanya berupa } \\
\text { balok kayu dan palu. }\end{array}$ & $\begin{array}{c}\text { Source yang menghasilkan gelombang } \\
\text { berada di atas permukaan, sehingga } \\
\text { gelombang perlu melewati banyak } \\
\text { lapisan dan material untuk mencapai } \\
\text { transduser geofonnya. Hasilnya dapat } \\
\text { mengecoh. }\end{array}$ \\
\hline 2. & & $\begin{array}{l}\text { Karena pengujian yang dilakukan } \\
\text { hanya pada satu lubang bor, maka tidak } \\
\text { ada kesulitan untuk menaikkan alat } \\
\text { setiap } 1 \text { meter. }\end{array}$ & $\begin{array}{l}\text { Source yang dihasilkan adalah hasil dari } \\
\text { pukulan palu secara manual yang } \\
\text { dilakukan oleh tiga orang berbeda } \\
\text { sehingga hasil pukulan tidaklah konstan } \\
\text { sama besarnya. }\end{array}$ \\
\hline
\end{tabular}


Besaran gelombang yang dihasilkan dari source konstan sama karena

1. dihasilkan dari piston yang melakukan pergerakan yang sama untuk setiap gelombang yang dihasilkan.
Membutuhkan lubang bor lebih dari kedua pengujian lainnya sehingga membutuhkan biaya lebih mahal.

\section{Crosshole Seismic}

2.

1.

2.

P-S Suspension
Karena peletakan source dan transduser geofon yang berada pada kedalaman yang sama, maka semakin sedikit lapisan ataupun material yang perlu dilewati oleh gelombang tersebut, sehingga hasil yang didapatkan lebih tidak mengecoh.
Kesulitan peletakan source dan transduser geofon yang perlu berada di kedalaman yang sama dengan arah tertentu pada lubang yang berbeda.
Besaran gelombang yang dihasilkan dari source konstan sama karena dihasilkan dari piston yang melakukan pergerakan yang sama untuk setiap gelombang yang dihasilkan.
Peletakan source yang bertempatan lurus tepat di bawah transduser geofon dalam satu lubang bor membuat gelombang yang diterima oleh geofon menjadi membingungkan karena gelombang yang sampai terlebih dahulu belum tentu gelombang yang diharapkan.
Karena pengujian yang dilakukan hanya pada satu lubang bor, maka tidak ada kesulitan untuk menaikkan alat setiap 1 meter.
Karena peletakan transduser geofon berada di atas source, maka semakin tinggi titik kedalaman uji mendekati permukaan, semakin sensitif pula geofon menerima gelombang dari aktivitas di atas permukaan dibandingkan gelombang yang dihasilkan oleh source.

\section{DAFTAR PUSTAKA}

\section{ASTM D 4428 / D 4428M - 07. (Crosshole Seismic Testing)}

\section{ASTM D 7400 - 08. (Downhole Seismic Testing)}

Geovision. Suspension P-S Velocity Logging Method. Tersedia di www.geovision.com (2 Februari 2019).

Hunt, Roy E. 2005. Geotechnical Engineering Investigation Handbook: Second Edition. America: Taylor \& Francis Group, LLC.

Ibrahim, Gunawan dan Subarjo. 2005. Pengetahuan Seismologi. Jakarta: Badan Meteorologi dan Geofisika

Kramer, Steven L. 1996. Geotechnical Earthquake Engineering. America: Prentice-Hall, Inc.

Olson Engineering. Crosshole/Downhole Seismic (CS/DS).

Olson Instruments. Crosshole/Downhole Seismic (CS/DS).

Telford, W. M. dkk. 1990. Applied Geophysics: Second Edition. America: Press Syndicate of the University of Cambridge. 
Perbandingan Hasil Eksperimen Downhole Seismic, Gebby Pandu, et al. Crosshole Seismic, dan Modifikasi Alat P-S Suspension dengan Hasil Korelasi Data N-SPT dan CPT 